\title{
The future of healthcare systems
}

\author{
Information technology and consumerism will transform health care worldwide
}

$\mathrm{E}$

xtrapolation of current trends is a poor way to think about the future, particularly at times of great change. The best method, according to Ian Morrison, former president of the Institute for the Future in California, seems to be to bring together a diverse group of people knowledgeable about the subject of interest, provide them with good data, and ask them to imagine a series of possible scenarios. Earlier this year Andersen Consulting, the world's largest management consulting firm, invited 25 people from different parts of health care and from 10 countries to Singapore to consider how the world's healthcare systems might develop.

The group was particularly interested in what part "managed care" might play. The World Bank has argued that it has much to offer internationally, and many American managed care organisations have already begun to operate outside the United States. One of the main conclusions of the meeting was that the whole system of managed care (if there is such a thing) had little to offer but that the many tools of managed care (see box) had much to offer most healthcare systems.

Although every healthcare system is different, they can be grouped into four "archetypes." Socialised medicine (as in Britain or Sweden) covers everybody, has a single payer, and usually has those who provide care salaried or capitated (paid so much for every person for whom they provide care). Socialised insurance (as in Australia, Canada, or France) also covers everybody and has a single payer but pays those who provide care a fee for each service. Mandatory insurance (as in Germany, Brazil, Japan, Malaysia, and Singapore) again covers everybody but has multiple sickness funds or insurance carriers and provides care through a mixture of salaried public providers and private providers paid a fee for each service. Voluntary insurance (as in the United States or South Africa) does not offer cover to everybody

$$
\begin{array}{lr}
\text { Some tools of managed care } \\
\text { - Managing demand } & \text { Pre } \\
\text { Capitation } & \text { Dis } \\
\text { Gatekeepers } & \text { Great } \\
\text { Advice lines to } & \text { patients } \\
\text { User fees } & \text { - Ca } \\
\text { Consumer education } & \text { Tel } \\
\text { - Medical management } & \text { Great } \\
\text { Review of use } & \text { r }
\end{array}
$$

and has many payers and providers and different systems of payment and delivery.

No healthcare system in the world is stable, and everybody at the meeting thought that all systems would undergo considerable change in the next 10 years. The drivers of change in the developed world are reaching the limits of the welfare state, exhausting traditional methods and tools for containing cost, and experiencing increased consumer sophistication and demands. Change is being driven in the developing world by the growth of the middle class, greater demands from that middle class, and the globalisation of economies (as those countries are more exposed to what the developed world has to offer and experience greater competition and economic pressure within their own economies).

Change in the United States is being driven by rising costs, the failure to provide universal coverage, consumer dissatisfaction, and the increasing recognition that the country has poor life expectancy and high infant mortality despite an expenditure on health care far higher than any other country. The main response in the United States has been the growth of managed care. It might be defined as "the arrangement whereby an organisation assumes responsibility for all necessary health care for an individual in exchange for fixed payment" but is probably best seen as a collection of techniques for containing cost and raising quality. More than half of Americans now receive their health care through managed care schemes broadly defined, many of them run by for profit organisations. Managed care markets in the United States are becoming saturated, and a further driver of change worldwide is the enthusiasm of managed care companies to find new markets.

The group was able to imagine six future healthcare systems. The first was socialised medicine but with increased incorporation of the tools of managed care (Britain's NHS already includes many of these- such as capitation and gatekeeping-and is in many ways one giant managed care system). The new tools that will be introduced include those used for managing demandfor example, advice lines to patients, user fees, and consumer education. Socialised medicine may also come to use the tools of medical management, including utilisation review (doctors have to seek permission before referring patients or expending large sums of money), preadmission certification (approval by those paying the bills before a patient is admitted to hospital), and disease management (setting up systems to ensure more cost effective care of patients with chronic diseases). Managed care also has tools for the delivery of care, including tele- 
medicine and greater use of guidelines and non-doctors for managing patients. British and Swedish doctors may wince at the thought of these tools being introduced into their systems, but it is hard to see how governments desperately trying to contain public expenditure and meet the rising demands for health services will be able to resist them. The group also thought that countries with socialised systems would experience increased pressure for growth of private care.

The second scenario was of a "managed mandatory system" where multiple sickness funds were exposed to competition, merged, and linked together by technology into a "virtual single payer." This system-which might emerge in Germany and Japan-would also use the managed care tools of demand management, medical management, and care delivery.

The third scenario may apply in countries like Singapore that now have a per capita gross national product comparable to that of many developed countries but which spend only about $3 \%$ of their gross national product on health care. These countries are keen to avoid the "trap" of an insatiable welfare state and would prefer to keep their spending on health care low. Singapore, which is keen to encourage "personal responsibility," has mandatory personal saving for health care, and employees must pay for some of their health care out of their personal account. The government hopes that this device will discourage inappropriate use, but Singaporeans can go directly to specialists-and increasingly do. These countries are unlikely to be able to resist the pressure for increased health spending, but some of the tools of managed care may help them.

The fourth scenario is of a multitiered health service with private, fee for service medicine at the top; American style managed care funded from social insurance in the middle; and lower quality, government funded care at the bottom. Some predict that all health systems, including that of the United States, will converge to this model, which is seen commonly in Latin America.

The fifth scenario described a system very different from anything that exists now-"an integrated and virtual" system. This system has been foreseen by forums organised by Andersen Consulting in Australia and may be brought about by new entrants to health care and by transformational use of information technology. The new players include corporations like Disney and Microsoft, which have very different ideas from existing players on how health care might be delivered. The Australians saw four futures: one where new players and transformational technology were resisted, two where only one or the other flourished, and the final one where both flourished. They opted for the integrated and virtual system, where both flourish, because they could not see these forces being resistedbut is not clear what the system may look like. They imagine that services will be provided "anywhere, anytime" by healthcare providers, suppliers, funders, insurers, and consumers working in new sorts of organisational relations. Government will become a regulator rather than a provider. Providers will focus on long term relations, and the consumer role will be much greater than now. This integrated and virtual system could operate within more familiar systems, including with a system like an enhanced NHS.

The centrality of consumers is the main characteristic of the sixth scenario-"the informed consumer."

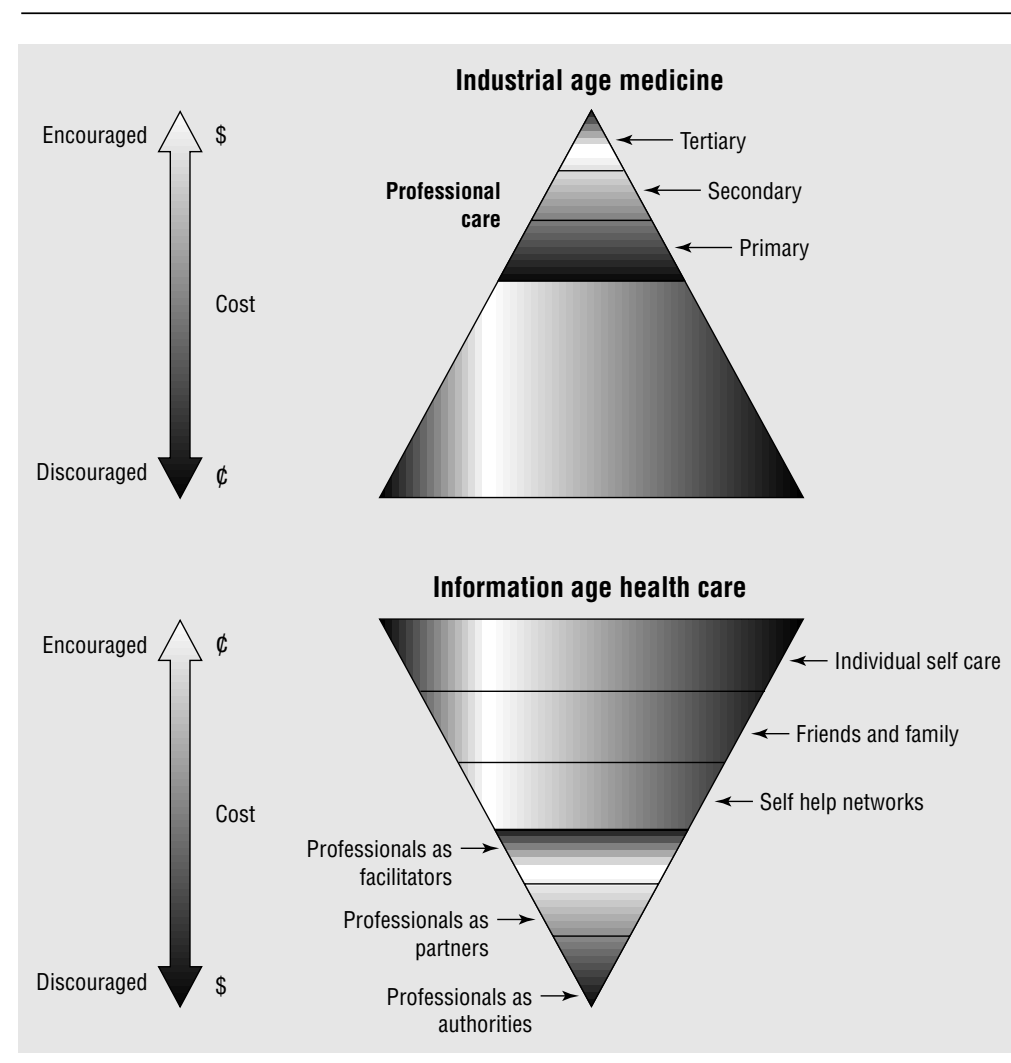

Fig 1 How "industrial age medicine" will invert to become "information age healthcare" (reproduced with permission from Jennings, Miller, and Materna) ${ }^{1}$

This is a form of health care that might operate within any other system. Consumers will use information technology to access information and control their own health care, consulting professionals much less often. Figure 1 shows how "information age health care" inverts the traditional pyramid of "industrial age medicine." Instead of being viewed as the apex of a system of care that hardly recognises the large amount of self care that occurs now, professional care will be viewed as the support to a system that emphasises self care. Healthcare providers will progress in this world from managing disease to promoting health, and they will do this through lifetime plans that are built on intimate and detailed knowledge of customers.

Perhaps none of these scenarios will emerge, but some of the developments imagined within them probably will. Doctors think that they have been living through years of uncomfortable change, and they have. But the pace of change is unlikely to slow, and our health systems will probably see more changes in the next 20 years than in the past 20. Most large sectors of developed economies-transport, manufacturing, and telecommunications-have been transformed in the past 20 years. Health care has not but surely will be.

\section{Richard Smith Editor}

$B M J$, London WC1H 9JR

1 Jennings K, Miller K, Materna S. Changing health care. Santa Monica:

Richard Smith and all the other participants had their expenses for the Singapore trip reimbursed by Andersen Consulting. 


\title{
Managing diabetes after myocardial infarction
}

\author{
Time for a more aggressive approach
}

See $\mathrm{p} 1512$

$\mathrm{T}$ The Diabetes Control and Complications Trial (DCCT) produced clear evidence that intensive management of insulin dependent diabetes helped delay the onset or progression of microangiopathic complications of diabetes. ${ }^{1}$ This major randomised control trial confirmed and extended observations from smaller studies of the relation between diabetic control and the development of small vessel disease and neuropathy. However, no previous studies have argued convincingly for a relation between diabetic control and macrovascular disease, which remains the major cause of mortality in diabetic patients and makes a substantial contribution to morbidity. The Diabetes Control and Complications Trial came closest to this conclusion when reporting a highly suggestive, but non-significant $(\mathrm{P}=0.082)$, reduction in macrovascular events in the intensive treatment group. ${ }^{2}$

In patients with non-insulin dependent diabetes the situation is less clear, with evidence still awaited for a relation between diabetic control and microvascular complications. Furthermore, since these patients are hyperinsulinaemic, researchers have hesitated to subject them to intensive insulin regimens; since hyperinsulinaemia is associated with atherogenesis, increasing circulating insulin concentrations might actually increase the mortality from macrovascular disease. ${ }^{3}$

The three year follow up results of the DIGAMI trial, published in this week's BMJ (p 1512), are therefore of particular importance, as they provide evidence that mortality in diabetic patients who have a myocardial infarction is reduced by the immediate use of glucose and insulin infusion followed by a multidose insulin regimen. ${ }^{4}$ After a mean follow up time of 3.6 years, patients randomised to receive a glucose and insulin infusion showed an $11 \%$ reduction in mortality, that is a reduction in relative risk of 0.72 . These results extend the one year follow up results in this cohort, which showed a reduction in mortality, both overall and in hospital. ${ }^{5}$

Several arguments have been put forward to explain the increased mortality in diabetic patients after myocardial infarction: more extensive and premature coronary atherosclerosis with a predilection for smaller vessels; greater impairment of left ventricular function, possibly as a result of reduced compliance from muscle protein glycation; and autonomic neuropathy with effects on heart rate and pain perception. There are also strong theoretical grounds for assuming that controlling blood glucose after myocardial infarction should improve outcome. The metabolic consequences of a myocardial infarction-increased insulin resistance from circulating catabolic hormones and additional insulin deficiency from adrenergic effectslead to impaired substrate supply and raised concentrations of non-esterified fatty acids. These fatty acids have been implicated in cardiac arrhythmias, but, perhaps more importantly, they uncouple oxidative phosphorylation, inhibit myocardial membrane ATPase, and increase myocardial oxygen consumption.
This results in a shorter action potential, reduced cardiac function, and increased infarct size. ${ }^{6}$ In addition, there are many abnormalities of platelet function, fibrinolysis, and viscosity in diabetic patients after myocardial infarction that are related to the metabolic disturbance and which are partially corrected by good control of blood glucose.

It is therefore logical to ascribe the differences in mortality between groups in the DIGAMI study to the introduction of insulin both in the short and longer term. However, before unqualified acceptance of this conclusion, we should consider a somewhat unexpected finding-that the patients with reduced mortality in hospital and at three years were those categorised as low risk and were not taking insulin at the time of their infarct. Could it be that it was not strictly the insulin which was beneficial but the withdrawal of other treatment (and replacement by insulin)?

What are the implications of this study? Undoubtedly, insulin infusion and insulin treatment of diabetes should become part of a more aggressive approach to managing diabetic patients after myocardial infarction. Attempts to improve management in this area have been bedevilled by an unjustified reluctance to translate evidence into practice or, perhaps with somewhat greater justification, to extrapolate from the nondiabetic situation. Thus, thrombolysis, probably the single most important measure and one that has been shown to almost halve mortality in hospital after infarction, ${ }^{7}$ is withheld because of vague fears of its impact on diabetic retinopathy; and other agents that have been shown to be of benefit in diabetic patients, such as $\beta$ blockers, are not used because they alter the lipid profile or mask hypoglycaemic symptoms, minor considerations in both effect and importance when set against mortality. Angiotensin converting enzyme inhibitors, aspirin, and cholesterol lowering drugs might also form part of this more aggressive package of care. Hopefully, the findings of this present study do not flounder on a reluctance on the part of either patients or doctors to introduce insulin.

Malcolm Nattrass Consultant physician

Selly Oak Hospital, Birmingham B29 6JD

1 The Diabetes Control and Complications Trial Research Group. The effect of intensive treatment of diabetes on the development and progression of long-term complications in insulin-dependent diabetes mellitus. N Engl J Med 1993;329:977-986.

2 The Diabetes Control and Complications Trial (DCCT) Research Group Effect of intensive diabetes management on macrovascular events and risk factors in the diabetes control and complications trial. Am J Cardiol 1995;75:894-903.

3 Stout RW. The effect of insulin on the incorporation of D-glucose-U14C into the lipids of the rat aorta in vivo. Horm Metab Res 1975;7:31-4.

4 Malmberg K for the DIGAMI study group. Prospective randomised study of intensive unsulin treatment on long term survival after acute myocardial infarction in patients with diabetes mellitus. BMJ 1997;314:1512-5.

5 Malmberg K, Ryden L, Efendic S, Herlitz J, Nicol P, Waldenstrom A, et al. Randomized trial of insulin-glucose infusion followed by subcutaneous insulin treatment in diabetic patients with acute myocardial infarction (DIGAMI study): effects on mortality at 1 year. $J$ Am Coll Cardiol 1995;26:57-65.

6 De Leiris J, Opie LH, Lubbe WF. Effects of free fatty acid and enzyme release in experimental myocardial infarction. Nature 1975;253:746-7

7 Lynch M, Gammage MD, Lamb P, Nattrass M, Pentecost BL. Acute myocardial infarction in diabetic patients in the thrombolytic era. Diabetic Med 1994;11:162-5. 


\title{
At last, a public health minister
}

\author{
Now we need a new public health act
}

$\mathrm{T}$ he appointment of Britain's first minister of public health, Tessa Jowell, is a sign that the new Labour administration recognises that the health of the population depends on more than the provision of good healthcare services. Health also depends on the physical, social, and economic environment in which people live. To improve public health the new minister will need to generate a culture of concern for human health throughout government policy. To facilitate this a new public health act should be introduced as soon as possible, and, pending that, changes should be implemented that do not need legislation.

The forthcoming British presidency of the intergovernmental conference of the European Union should focus its efforts on revising clause 129 of the Maastricht agreement (which deals with public health issues). This would make health impact assessment (which includes both environmental and social assessment) a dominant feature of the development of European policy, providing an evidence based counterbalance to market forces and the common agricultural policy. Given political commitment and improved methodology, health impact assessment could catalyse the next leap in the population's health in the early years of the new millennium.

The Beveridge report, the foundation stone of the NHS, emphasised the role of government in prevention. ${ }^{1}$ Unfortunately, the NHS's first half century saw little effective preventive action by parliament to reduce the great new epidemics such as heart disease and cancer and the consequent burden on the healthcare system. In 1976 Labour's policy document, Prevention and Cure: Everybody's Business, ${ }^{2}$ and the Conservative's 1992 Health of the Nation, ${ }^{3}$ exhorted people to modify their behaviour. But neither initiative included measures that only government can take, such as banning tobacco advertising and regulating commercial interests that damage health. The Labour party's majority in government and its stated commitment to public health provide an opportunity to emphasise health in public policy.

Many of the actions that governments can take to improve public health (see box) do not come within the responsibilities of the Department of Health. So the new minister of public health faces a massive task as the advocate for human health across government departments. She will need support from the best

\section{How governments can improve public health}

- Through greater social justice and reduced

inequality

- By better education

- By assessing the health impacts of all government

policy and programmes and adding health gain to them

- By implementing specific public health programmes and controls

- By improving healthcare services scientific evidence available and will have to overcome considerable inertia and vested interests. A public health act would provide her with the necessary authority and mechanisms, as well as legislation to implement a range of commitments.

\section{... and a royal commission on public health}

The government must examine its sources of advice on public health. The role played by successive chief medical officers has been of considerable public benefit over the past 80 years. But the recent decline in the office's support facilities and staff, and the deafness of some ministers to confidential advice they do not wish to hear, introduces a need for additional, more open advice on public health. A permanent royal commission on public health, reporting regularly to parliament on public health problems and evidence based solutions, could enjoy similar responsibilities to the Royal Commission on Environmental Pollution, the Law Commission, and the Audit Commission. It would provide a prestigious, independent, and public source of scientific information about problems and best practice. The quality of its research and evidence base could be audited via review of its recommendations five years after implementation

Health impact assessment should become a routine part of the evaluation of government policies and programmes and should be more widely required in planning and commercial regulation. This emerging methodology provides a means of identifying, predicting, and evaluating the likely positive and negative changes to health, social, and environmental risks for a defined population arising from proposed or existing policies, programmes, or projects. It will shortly be the subject of a report from the BMA Board of Science and Education. ${ }^{4}$ By requiring such an assessment prospectively and auditing the health effects some time later, the public health act would force policy makers and commerce to give far greater thought to how they can achieve health gain and avoid adverse effects on health.

While we await the passage of such an act, some changes could and should be introduced under existing powers. The proposed ban on tobacco advertising, for example, should include sports sponsorship, replacing it with support from the windfall savings on advertising and a new health tax on cigarettes as in Australia. "Alcopops" could be dealt with similarly. Other areas needing legislation include levels of alcohol intake and driving, and the failure of water companies to fluoridate drinking water when requested by health authorities after proper consultation. A requirement for trains to provide facilities for bicycles, and improved access to the countryside for ramblers would be part of a package to facilitate walking and cycling. Rail and agriculture receive public subsidy, which could be withheld unless substantial public access is permitted. A health promotion lottery fund could, over time, provide 
accessible swimming and other sports facilities in every community. Legislation on communicable diseases, food safety, trading standards, and health and safety need early attention. A comprehensive occupational health service, available to companies and trade unions at marginal cost, would provide a cost beneficial addition to the NHS. Improvements in nutrition require a near doubling of the fruit and vegetable consumption of Britain's population. Achieving this would alter patterns of food production and provide new opportunities to agriculture and industry. ${ }^{5}$

Britain's public health advocates-the chief medical officer and directors of public health, as well as occupational health physicians and school nurses-need to be protected by legislation, but initial moves are possible. Recent experience of managerial and other pressures on public health advocates suggests that the safeguard of an appeal, perhaps to a royal commission, might be needed if undue political, administrative, or commercial pressure prevented a doctor or nurse from highlighting evidence based public health problems and solutions. The General Medical Council could also review its guidance to doctors on reporting public health problems.
Finally, the public health act could provide a platform from which the minister, with advice from the chief medical officer or the royal commission, could introduce regulations to deal with emerging public health problems, implement evidence based action, or combat inequity in social welfare. The act would remedy a major deficiency in Britain's health system. Together with the revised and revitalised Maastricht clause 129, it could greatly improve the population's health and quality of life.

\section{Noel Olsen Public health physician}

Oakdale, Courtwood, Newton Ferrers, Devon PL8 1BW

\footnotetext{
1 Beveridge report. Social insurance and allied services. Command paper 6404 London: HMSO, 1949

2 Department of Health and Social Security. Prevention and Health Everybody's business. London: HMSO, 1976.

3 Secretary of State for Health. The Health of the Nation. A strategy for health in England.London: HMSO, 1992.

4 Health and environmental impact assessment: an integrated approach. A report of the BMA Board of Science and Education. London: BMA, (in press).

5 National Heart Forum. At least five a day: strategies to increase vegetable and fruit consumption. London: HMSO, 1997.
}

\section{Requesting necropsies}

\section{Greater humanity and awareness of suffering will help doctors and patients alike}

A s medicine increasingly acknowledges and even welcomes the active participation of patients and their families in medical care, it is timely to investigate the attitudes of relatives towards necropsies. Any request for a necropsy is necessarily conducted at a time of greatest grief, distress, and uncertainty; and those deaths where a necropsy is required are often those where the bereavement is sudden or otherwise traumatic, and thus likely to be associated with shock, denial, and dissociation. The relatives' mental state is likely to make the request more difficult to deal with and the ultimate outcome of the loss more problematic. ${ }^{1}$ Thus, requests may be countered with anger, resentment, or rejection.

Attitudes towards necropsy are shaped by personal and cultural attitudes towards death and medical science and by the context in which a request is made. Studies suggest that a common source of discomfort is the thought of the dead body being cut up, or the fear that the person may "wake up" during the necropsy. ${ }^{2}$ This is reflected in reasons for refusing necropsy: in one study $83 \%$ of relatives felt that "the patient had suffered enough."

In a recent study Start et al suggested that this most complex of tasks is increasingly falling to junior staff. ${ }^{4}$ In addition to the obvious implications for the relatives in being asked by less experienced clinicians, this must inevitably exacerbate the stress experienced by junior staff in having to convey bad news. ${ }^{5}$

Although medical staff may see their main task as "getting the necropsy," the crucial thing for families is obtaining appropriate feedback about its results. Considerable delay may occur in communicating results to medical staff, let alone families, ${ }^{6}$ and one study found that only half of those who consented to a necropsy after perinatal death were satisfied with the presentation of the findings.?

Redressing the problem requires not only a sophisticated approach to the needs of relatives, but also an understanding of doctors' own attitudes towards death, dying, and the postmortem examination. The traditional apocryphal stories about cadavers, disseminated by medical students, probably reflect an attempt to deal with the "decay, death, and dismemberment" that confront students as they embark on anatomical learning. ${ }^{8}$ A survey of medical students confirms that three quarters of them felt uneasy when they attended a necropsy or when they contemplated one on themselves. ${ }^{9}$ These reactions are no doubt tempered by the students' own experience of loss, death, and dying and any opportunity they may have had to work through these complex emotions. One under-researched cause of uneasiness among doctors may be that necropsy is seen as "the final audit"-which may not always reflect well on clinical diagnosis and management of patients.

Clinicians' skills requesting permission for necropsy need to be improved. These skills are usually acquired haphazardly, through personal experience with a smattering of help from senior colleagues. ${ }^{10}$ Such practices not only undervalue the traumatic impact of such work on junior staff but are a failed opportunity for preventing psychological distress among the patients' family and among staff. They also perpetuate idiosyncratic or insensitive practices. There are recognised techniques for improving doctors' communication skills, ${ }^{11}{ }^{12}$ but evidence sug- 
gests a need for continuing medical education rather than a one off package ${ }^{13}$ the issue should also be addressed at an undergraduate level. Training videos and role playing situations should include messages about the emotional and traumatic impact of many of our interviews with patients. Our medical training must not be allowed to promote sophistication in biological sciences and acquisition of skills at the expense of humanity and awareness of suffering.

Jane Turner Senior lecturer

Mental Health Centre, Royal Brisbane Hospital, Queensland 4029, Australia

Beverley Raphael Director of mental health

Centre of Mental Health, New South Wales Department of Health, Locked Bag 961, Sydney 2060, Australia

1 Raphael, B. The anatomy of bereavement. Northvale: Jason Aronson Inc, 1994.
2 Sanner M. A comparison of public attitudes toward autopsy, organ donation, and anatomic dissection: a Swedish survey. JAMA 1994; 271:284-8.

3 Hinchliffe SA, Godfrey HW, Hind CRK. Attitudes of junior medical staff to requesting permission for autopsy. Postgrad Med J 1994;70:292-4.

4 Start RD, Sherwood SJ, Kent G, Angel CA. Audit study of next of kin satisfaction with a clinical necropsy service. BMJ 1996;312:1516.

5 Firth-Cozens J. Emotional distress in junior house officers. BMJ 1987;295:533-6.

6 Simpson CG. Communicating necrospy results. BMJ 1991;303:1403.

7 Rahman HA, Khong T. Survey of women's reactions to perinatal necropsy. BMJ 1995;310:870-1.

8 Hafferty FW. Cadaver stories and the emotional socialization of medical students. J Health and Soc Behavior 1988;29:344-56.

9 Sanner MA. Medical students' attitudes toward autopsy. How does experience with autopsies influence opinion? Teaching Pathology and Laboratory Medicine 1995;119:851-8.

10 Sherwood SJ, Start RD, Birdi KS, Cotton DWK, Bunce D. How do clinicians learn to request permission for autopsies? Med Education 1995;29:231-4.

11 Fallowfield L. Giving sad and bad news. Lancet 1993;341:476-8.

12 Buckman R. How to break bad news. A guide for health-care professionals. London: Papermac, 1992.

13 Maguire P. Can communication skills be taught? Br J Hosp Med 1990;43:215-6.

\section{Meet Minerva in cyberspace}

\section{The BMJ's web site celebrates its second birthday}

$M$ inerva is the BMJ's best loved section. Unsurprisingly, it is also the section that visitors most want to read on our internet web site. To mark the site's second birthday we have decided to grant them their wish. From this week Minerva will be available, in her entirety, at www.bmj.com.

Over the past two years we have moved from our original policy of posting only limited material from each week's journal. First, we added all the jobs that are advertised in our classified supplements. Next, we began bundling together full text articles on similar topics. Our first foray was a collection of all the papers relating to bovine spongiform encephalopathy and the new variant of Creutzfeldt-Jakob disease that had appeared in the BMJ since 1988. Full archives of articles that have appeared in our monthly section Information in Practice are available from our web site, as are all the articles from Career Focus in our classified advertisement supplement. The catalogue of With Head Eं Heart Eं Hand, Nick Sinclair's photographs of 20th century British doctors, ${ }^{1}$ can be viewed by readers unable to visit London's National Portrait Gallery. The mix seems to be working-each week the web site receives about 10000 visitors from 90 countries, twice as many as a year ago.

Two years ago we were one of only 110000 web addresses competing for visitors' attention. The total has grown 10-fold since then, at a rate of one new web site every minute over the past year (internet domain survey, www.nw.com). Among the new arrivals are web sites devoted to the BMJ Publishing Group (www. bmjpg.com), each of the group's 25 specialist journals, and the BMA (www.bma.co.uk).

The pace of technological innovation, however, is outstripping even the increases in traffic and destinations. People now talk of internet years rather like dog years, with each year in cyberspace equalling seven years elsewhere. An indication of where things are heading is evident from our web site. As well as full text Minerva and a modest redesign, visitors this week will find an advertisement for a technology partner. We are looking for a company to help us exploit the new features that have become available to electronic publishers. The advertisement appears only on our web site, and we expect that most negotiations will be conducted entirely electronically.

By the end of this year we hope that the full text of Minerva will be joined on our web site by the full text of the entire current issue. This will be supplemented by an easily searchable archive containing the past 10 years of journals. Readers will be able to print out articles that look exactly as they do on the journal page. References in papers will be linked directly to their Medline abstracts. Readers will have the chance to comment on each article, and their email responses will be listed after the relevant article almost as soon as they are submitted. This will circumvent the problem of limited space for letters in the paper journal, which results in our publishing fewer than a third of submitted letters, and those usually two or three months late.

The $B M J$ was the world's first general medical journal to have a substantial presence on the internet. Two years on we remain convinced that this new medium will play an important part in our future and that our readers deserve the best that the medium has to offer. Enjoy Minerva.

Tony Delamothe Web editor

BMJ, London WC1H 9JR (bmj@bmj.com)

1 Sinclair N. With head $\mathcal{E}$ heart $\mathcal{E}$ hand. London: BMJ Publishing, 1997. 